\title{
Comunicação e Usos do Passado
}

Aula inaugural do PPGCOM da UERJ - 6 de maio de 2015

Marialva Barbosa (UFRJ) 
Inicio essa reflexão a partir de dois pressupostos que, só em aparência, são contraditórios. $\mathrm{O}$ primeiro diz respeito à característica que se constitui numa espécie de marca dos estudos de comunicação: o presentismo. $\mathrm{O}$ segundo parte do diagnóstico de que há hoje a exacerbação das representaçôes do passado nos meios de comunicação.

Num tempo de aceleração temporal exponencial e diante de um mundo que não admite a existência de projetos e perspectivas futuras, vivemos o alargamento do presente de tal forma que o futuro nele já se inclui. Um tempo cujo presenteísmo substituiu definitivamente o futurismo. Talvez isso explique a característica dos estudos da comunicação, nos quais o valor do passado ocupa lugar secundário nas preocupaçóes teóricas e empíricas.

Se de um lado há esse diagnóstico, de outro, observa-se cada vez mais o passado como valor preponderante nas narrativas midiáticas. E o que está em jogo nessa explosão é o papel que os meios de comunicaçáo se auto atribuem como lugar na história. Assim, ainda que procurem fortalecer a imagem do imediatismo daquilo que divulgam, fazem não só vários usos do passado, como também se instituem como produtores da história do tempo presente. Além disso, ao selecionarem fatias do mundo como se fosse o mundo, articulam discursivamente o que deve ser considerado passado numa perspectiva futura.

Portanto, o que se discute é a forma como o passado é apresentado em diversos suportes midiáticos e de que maneira passa a ser publicizado. $\mathrm{O}$ que está em jogo, também, é a quem afinal pertence a narrativa sobre o passado.

Essa pergunta ganha maior densidade num mundo governado pela midiatização, em que, como enfatiza Muniz Sodré (2014), formas de vida virtualizadas substituem a cotidiana existência pautada pelas açôes comuns. Essas virtualizaçáo e midiatização da vida produzem alguns sintomas marcantes da nossa época tais como o alargamento da percepçâo do tempo que denominamos presente; a eclosáo de um individualismo exacerbado; a consciência da ação destruidora humana; a nostalgia do passado e de sua documentação que passa a ser signo de validação do próprio ser no mundo; e, finalmente, o término da ideia de futuro como promessa.

A pergunta que deveríamos fazer é até que ponto essa aceleraçáo temporal, marca de um mundo que se define como ultra instantâneo, produziria uma articulação particular do passado com o presente e o futuro?

\section{Usos do passado no presente}

Falar dos usos do passado na comunicação é, portanto, se referir a três questôes fundamentais. A primeira leva-nos a perguntar quais seriam as razóes que fazem o passado a ser objeto de comunicação, seja na produção da mídia de maneira geral, seja no acionamento realizado pelas instituiçóes em suas açóes voltadas para o público interno e/ou para o externo. Ou seja é preciso pensar como e porque o passado é estratégico.

A segunda refere-se à construção do mapa dos usos que as instituições, 
tanto os meios de comunicação como organizaçóes as mais variadas, têm feito do passado. De que forma vem sendo utilizado e quais as estratégias narrativas empregadas para trazê-lo para o presente? E, por último, que cuidados se deveria ter ao transformar o passado em estratégia de comunicação. Devemos percebê-lo como uma imagem mental ou achar que de fato houve um passado? O passado a que nos referimos é o verdadeiro, o único possível, ou apenas a fatia de um tempo que se acreditou existir? Mas afinal o que é o passado?

Podemos chamar de passado a matéria da história, ou seja, um tempo que existiu e que restos e rastros parecem indicar a sua presença (HELLER, 1993 e RICOUER, 2007).

A disciplina histórica, ao se ocupar das ações dos homens no tempo e não estrito senso do passado, produz como matéria essencial para sua inscrição o tempo calendário. E é por meio dele que determinamos as épocas, as fases, as datas numa linha artificial que passa a ser sucessiva e datada (RICOEUR, 2007; POMIAN, 1984). Mas cada época histórica tem uma forma particular de experimentar o passado. É no processo de vida, na distinção que se faz em relação ao que já foi vivido, que se constrói o tempo histórico, tempo dos sujeitos e das açóes do homem no mundo.

Ao se experimentar, hoje, o tempo como algo sempre novo, inédito, em que alteraçôes cada vez mais rápidas exigem adaptações também muito mais rápidas, se está, na verdade, alargando o presente e nele introduzindo o futuro. Vive-se uma espécie de eterno presente. $\mathrm{O}$ presente não é apenas o agora isto é um tempo que se diferencia do que já terminou, o passado - mas o que está ainda por vir. Constrói-se uma fronteira, uma linha artificial que divide aquilo que já aconteceu (o passado) daquilo que se está vivendo (um presente sem fim). O passado é, assim, percebido como algo radicalmente diferente do presente. E nesse sentido, transforma-se também em novidade.

Assumir o pensamento histórico é reconhecer que o passado faz parte de um longo processo, em que açóes que passaram continuam durando. Por outro lado, tudo aquilo que se pode qualificar como passado é produzido dentro de determinados parâmetros oriundos do presente. Ou seja, o passado é processual e assim deve ser recortado, determinando períodos, procurando congelá-lo como um objeto, escolhendo personagens para falar desses tempos de outrora. Visualiza-se e escolhe-se grupos ou pessoas, unidades políticas, sociedades pequenas ou complexas. Arbitrariamente, mas de maneira absolutamente necessária, produz-se recortes para o particularizar. Mas o que se estuda é sempre um processo e açôes humanas.

Em relação aos meios de comunicação, podemos dizer que os usos do passado não é algo que novo em suas formulações narrativas ${ }^{1}$. Ainda que no senso comum se tenha a ideia de que os meios de comunicação privilegiam os acontecimentos do presente e que na contemporaneidade o ultra-atual ganha destaque na cena midiática, a rigor fazem do passado, desde muito, tema frequente de seus textos de cunho informativo ou daqueles de natureza ficcional.

Usando rastros e vestígios, fornecem um contraponto à necessidade 
permanente de inserção do público na atualidade do mundo. Os usos do passado que produzem - nas retrospectivas, nas datas comemorativas, nos textos informativos que relembram eventos semelhantes ocorridos, nas narrativas ficcionais das minisséries e telenovelas, nos sites e nos produtos dos ambientes digitais contemporâneos, entre dezenas de outras apropriaçóes - ganham um sentido particular num mundo governado pela aceleração exponencial do tempo.

Há que se considerar também que em função dos regimes de historicidade (HARTOG, 2014) de determinadas épocas, essas encenaçôes adquirem características peculiares. Num mundo marcado pela construção de um futuro que começa agora, expandindo o presente, o passado produz a ressignificação do próprio presente. Nessa perspectiva, há que distinguir um tempo radicalmente novo em relaçáo a esse presente que dura, pois inclui nele o futuro. $\mathrm{E}$ esse tempo novo é o passado.

Podemos considerar que nossa época, exacerbada de presentismo, deseja reincluir o passado no presente e, ao mesmo tempo, quer apagar qualquer sentido (ou desejo) de futuro como projeto. Em consequência, devemos concordar com François Hartog (2014, p. 148), que o presentismo substituiu o futurismo que se deteriorou. Mas é preciso perceber que esse presente não é nem uniforme, nem unívoco e que em função do lugar que se ocupa no mundo é vivenciado de uma ou de outra forma (HARTOG, 2014, p. 14). Se de um lado há o tempo dos fluxos, da aceleração e da mobilidade (HARTOG, 2014, p. 14), de outro há o tempo dos que continuam excluídos pela lógica perversa do capitalismo, em que se vivencia a permanência do transitório, nas relaçóes de precarização do trabalho, o presente sem passado dos deslocados, dos que vivem as múltiplas diásporas sociais e onde não há um futuro, já que o tempo dos projetos nunca esteve aberto para eles.

Num regime de historicidade definido majoritariamente pela lógica da aceleração vive-se, portanto, uma espécie de eterno presente. O futuro deixa de ser promessa para se tornar ameaça. Há o medo exponencial do futuro tal como foi concebido em regimes de historicidade anteriores, já que se pode esperar catástrofes terríveis, decorrentes de ação humana ao viver o presente como se fosse eterno ou se nele já estivesse contido o futuro.

Diante das utopias em torno das fantasias neoliberais da globalização da década de 1990, que se mostraram infundadas pelos acontecimentos monstruosos do mundo, como o 11 de setembro que inaugurou o século XXI, os imaginários sobre o futuro ficaram ainda mais fluidos e distantes.

\section{Usando o passado...}

Refletir sobre o valor que os meios de comunicação atribuem ao passado significa perceber, inicialmente, que as narrativas dos meios de comunicação já possuem nelas mesmas um desejo de futuro e são construídas visando a permanência e sua reutilização em outro momento. São produzidas como arquivos da e para a história. Portanto, as intencionalidades, as multiplicidades 
de vozes presentes nos produtos comunicacionais e, sobretudo, os processos que engendram devem ser conhecidos pelo pesquisador que queira se debruçar sobre a imprensa como arquivo do passado.

A segunda questão diz respeito ao formato narrativo. Tendo a pretensão de fixar o tempo, retirando do presente fatias as quais atribuem uma supra significação, representam como espelho do mundo, a rigor, pedaços de significaçôes do mundo. Os meios de comunicação participam da produção de sentidos no momento e no lugar de sua inserção a partir de critérios e valores diversos (e que se transformam sem cessar). Há sempre, contido nos documentos que produzem, múltiplas vozes que devem ser escavadas pelo pesquisador.

O terceiro aspecto diz respeito ao sentido de história adotado. Eivados do senso comum, o sentido de história que os meios de comunicação reproduzem é o de recuperação verdadeira, na perspectiva de que narrar o passado é trazê-lo incólume para o presente. Dependente da visão que carrega a perspectiva de verdade inquestionável, introduzem um discurso sobre o passado como narrativa privilegiada também como forma de atribuir valor as suas açôes. Assim, não é qualquer discurso sobre o passado que interessa, mas prioritariamente o que já foi narrado por eles mesmos. Referendam, então, o passado verdadeiro que foi construído, por exemplo, pela própria imprensa e reinserem, novamente, esse discurso na cena pública. As retrospectivas, as efemérides e os jogos de lembrança e esquecimento ocupam lugar preponderante nas suas narrativas porque o passado se reveste de um sentido supra-histórico que tem como função produzir valor de verdade.

O quarto ponto a ser enfatizado diz respeito ao desejo de futuro presente nas produçóes comunicacionais. Os meios de comunicação já produzem suas narrativas visando a sua re-apropriação no futuro, ou seja, como documentos para a história. É por isso que são recorrentes também as afirmativas que o jornalista seria o "historiador do instante" ou "o historiador do tempo presente", já que é ele quem relata o que se passa no mundo com um olhar que procura também interpretar o mundo ${ }^{2}$.

Essa é uma das razões de usarem múltiplas referencias ao passado: ao passado transformado em Nação em torno de um discurso comum, inclusive do ponto de vista de uma memória histórica partilhada; ao passado de sua própria história que nas suas construçôes se insere na história mais ampla da cidade ou do país; ao passado como utopia midiática, reconstruído como idílio dos tempos de outrora. As marcas escriturarias do passado - as roupas de época, as performances discursivas, os utensílios e adereços, as paisagens, etc. - se constituem em espécies de passagens em direção ao tempo pretérito.

\section{O passado cuidado}

Assim, o pesquisador que se aventura em se apropriar das narrativas dos meios de comunicação sobre o passado deve considerar que falam, sempre, tendo em conta a existência do verdadeiro passado. Tem-se a presunção de poder trazer, através de documentos e de restauraçóes das açóes presumidas dos 
homens de outrora, a significação do passado para o presente.

Claro que o passado só pode ser recuperado pelos sinais que permanecem durando, isto é, a partir de rastros e vestígios. Falar dele significa caminhar do agora numa direção pretérita seguindo esses traços. Significa considerar que esses rastros são signos de representação. Ou seja, não é possível recuperar o passado tal como ele se deu e sim apenas presumir como ele poderia ter sido.

Diante desses signos de representação procura-se interpretar o significado que possuiu e presumir açóes de homens que viveram outros tempos. Mas esses restos só perduraram porque foram atos de comunicação. Os restos do passado encontrados hoje são sempre durações das açóes de comunicação dos homens que passaram por aqui (BARBOSA, 2009).

Os meios de comunicação também representam o passado a partir da ideia cristalizada de linearidade absoluta. Ou seja, a noção dominante do senso comum sobre a história: a da sucessão absoluta dos tempos. O passado é representado linearmente e orientado para o momento axial mais singular, o presente. E isso através de diversas fórmulas narrativas como, por exemplo, das hoje populares "linhas do tempo", em que determinados fatos e personagens emergem produzindo um hiato numa história singular. Essa representação - uma verdadeira febre na produção das memórias institucionais - traz embutida a noção de que há um tempo que se sucede linearmente e que se pode também representar a passagem do tempo.

As representaçôes do passado através das linhas do tempo é sintoma de um tipo de história: uma história absoluta, verdadeira, que pode retomar o fio da meada da narrativa sobre o passado. Existe o pressuposto de um tempo linear e que, na sequência, com interrupçóes presumidas, se caminha para o presente como futuro já realizado. Reproduz a presunção de passagem homogênea do tempo e através do qual se pode caminhar. Esta representação supóe a ideia de que, vez por outra, emerge um evento singular, dotado de uma significaçáo supra-histórica e, por isso mesmo, digno de ser representado. Também existe na linha do tempo o arbitrário de determinar aonde aquela história teria começado. Afinal toda história que se conta deve ter um começo, um meio e um fim.

Há a busca pelo início primordial, aonde tudo teria começado. O momento fundador é elevado à categoria de tempo mítico. Essa busca pelo tempo primordial, o grande tempo, o começo absoluto decorre do mito que governa o pensamento ocidental de que a vida estaria contida entre a gênese e o fim dos tempos (KERMODE, 1966). Reproduz-se nas pequenas narrativas a grande intriga do mundo que busca de maneira incessante a origem, a gênese, aonde tudo teria começado.

O passado comum começa, pois, no momento zero marcado por um nascimento, aonde se tem o primeiro contato com o mundo. Buscar o início passa a ser o ato mais importante na localização do passado. Não basta percebê-lo, é preciso também narrar o grau zero de sua inscrição no mundo.

Outro cuidado que se deve ter ao considerar o passado diz respeito aos 
limites entre o verdadeiro e o verossímil. Com a presunção de que restaura o verdadeiro passado, o que os meios de comunicação produzem é a sua apresentação sob determinados parâmetros narrativos para que se tenha a impressão de se estar diante do único passado possível. É nesse sentido que o envolvem com o verossímil. Usando diversas mediaçóes, a televisão, por exemplo, nas narrativas ficcionais constrói uma imagem/imaginação que induz a pensar que se está recuperando o passado na sua totalidade, quando a rigor apresenta o verossímil. É pela fidedignidade visual que se instaura a ideia de passado real, porque verossímil.

Mesmo libertos da prova documental, nos textos ficcionais o quase passado, ou seja, aquilo que sabemos dele, continua regulando as possibilidades de sua representação. Não é possível representar um passado não conhecido e não reconhecido. É preciso ordenar a história e fornecer a crença de que só se poderia ter aquela história.

O último ponto a ser considerado, resulta da visão de história que se privilegia ao adotar a perspectiva de que o passado pode ser contado, com começo, meio e fim, ou seja, a forma como se considera a história.

Há muitas formas de considerar a história. Pode-se pensar que é possível recuperar o passado tal como ele se deu e que fazer história é trazê-lo para o presente, ou, ao contrário, pressupor que fazer história é produzir uma reinterpretaçáo imaginativa do passado. Nessa perspectiva, parte-se do pressuposto que sempre será produzida uma interpretação repleta das significaçóes construídas a partir do presente e das subjetividades dos que constroem atos narrativos sobre o passado.

Deve-se também ter o cuidado de não imputar aos homens de outrora um conhecimento que se tem hoje, ou seja, resguardando-se do anacronismo. Os homens do passado não tinham o conhecimento que possuímos e nem viveram até o momento presente de forma a se tornarem conhecedores da passagem do tempo (e da história).

Essas duas visôes diametralmente opostas de história - ou seja, o passado único e verdadeiro e o passado como possibilidade interpretativa - se refletem nas escolhas teóricas e metodológicas. No primeiro caso, os documentos atestam o valor do passado e não há espaços para as interpretaçóes. No segundo, percebe-se o passado também como imaginação histórica e como uma construção condicionada pelas vivências do presente.

A história, por outro lado, pode ser vista numa perspectiva diacrônica e nessa visão se sobressai a ideia de processo. $\mathrm{O}$ destaque será dado às mudanças, às transformaçôes. Já a perspectiva sincrônica destaca as continuidades. A rigor, continuidades e rupturas fazem parte do mesmo processo histórico.

Pode-se achar que o passado evoca o espírito de uma época e que cabe desvendar o que estaria por trás dos acontecimentos, revelando princípios. Pode-se achar também que fornece ensinamentos para o presente e que só é possível compreender o mundo se houver, como uma espécie de guia, as liçôes que forneceu. Mas também pode-se, ao contrário, achar que não há um 
princípio único para nenhum tempo da história e que também as açôes dos homens de outrora não servem de liçóes para o presente. Há, portanto, muitas formas de considerar a história e de perceber a relação comunicação e história

Termino essa fala com algumas perguntas que, a rigor, nortearam essa reflexão. Porque devemos pensar historicamente? Qual a importância de se inserir a perspectiva histórica dos estudos de comunicação? Porque isso seria importante para uma área que se caracteriza pela adoção de temáticas e reflexôes imersas no presenteísmo? Poderia alinhar diversas razóes, mas vou me restringir a apenas três.

A primeira diz respeito à questão mais fundamental do ser humano e que envolve as perguntas centrais da filosofia da história: o que somos, de onde viemos e para onde vamos?

A segunda, mais pragmática, levaria a olhar de maneira processual não apenas a nossa existência, mas o que produzimos enquanto conhecimento. Essa atitude obrigaria a, olhando para trás, considerar as reflexóes produzidas, o conhecimento acumulado, facilitando os movimentos empíricos e teóricos e, ao mesmo tempo, reconhecendo o saber como cumulativo e partilhado.

A terceira diz respeito à questão de que a história só pode ter a presunção de ingressar imaginativamente no passado, porque houve um tempo em que homens e mulheres vivendo a sua humanidade fizeram múltiplos gestos que, por serem, açôes de comunicação permaneceram durando. São as duraçôes das açôes de comunicação, fixando suas marcas, que tornam possível a perspectiva de um passado passando até o presente. Atos de comunicação dos homens de outrora são a história.

Pensar historicamente, portanto, mais do que permitir o adensamento da reflexão, é fundamental para a comunicação. Um olhar historiográfico obriga a perceber a condição humana como histórica. Afinal, a vida é sempre um ato de historicidade: não há possibilidade de se viver sem considerar que existe um mundo habitado por seres que podem viver conjuntivamente a mesma humanidade. 


\section{Referências Bibliográficas}

BARBOSA, Marialva. "Comunicação e história: presente e passado em atos narrativos". In: Comunicação, mídia e consumo. São Paulo: vol. 6, n. 16, p. 11-27, jul. 2009.

HARTOG, François. Regimes de historicidade. Presentismo e experiências do tempo. Belo Horizonte: Autêntica, 2014.

HELLER, Agnes. Uma teoria da história. Rio de Janeiro: Civilização Brasileira, 1993.

KERMODE, F. The sense of an ending: studies in the theory of fiction. Londres; Oxford; Nova Iorque: Oxford University Press, 1966.

LACOUTURE, Jean. "A história imediata”. In: LE GOFF, Jacques. $A$ história nova. São Paulo: Martins Fontes, 1993.

MATHEUS, Letícia Cantarela. Comunicação, tempo e história. Tecendo o cotidiano em fios jornalísticos. Rio de Janeiro: MauadX, 2011.

POMIAN, K. Lordre du temps. Paris: Gallimard, 1984.

RICOEUR, Paul. A memória, a história e o esquecimento. Campinas: Editora UNICAMP, 2007.

SODRÉ, Muniz. A ciência do comum. Notas para o método comunicacional. Petrópolis: Vozes, 2014.

\section{NOTAS}

(1) As ediçôes comemorativas, por exemplo, são práticas recorrentes nos jornais diários desde o final do século XIX. As que eram realizadas pelo Jornal do Brasil, por exemplo, recebiam o nome de Juiso do Ano, em textos ilustrados de Julião Machado, e ocupavam toda a primeira página do jornal antes mesmo da virada dos 1900 (Cf. Jornal do Brasil, 1 jan. 1901, p. 1). Sobre os usos do passado feitos pelo jornalismo cf. MATHEUS (2011).

(2) A expressão é de Albert Camus e é reproduzida por Jean Lacouture (1993). 